\title{
Pengaruh Fundamental Safe Work Practice Terhadap Pencegahan Kecelakaan Kerja Bagian Workover di PT. ACS Duri
}

\section{The Effect Implementation of Fundamental Safe Work Practice Injury Prevention Section Workover in PT. ACS Duri.}

\section{Saifullah* Nopriadi**}

\section{* Program Studi IKM STIKes Hang Tuah Pekanbaru, **PSIKM Fakultas Kedokteran UNAND}

\begin{abstract}
ABSTRAK
PT. Asrindo Citraseni Satria (ACS) adalah perusahaan yang bergerak dibidang minyak dan gas bumi dan merupakan sub kontraktor PT.CPI. PT. ACS telah menerapkan FSWP yang mempunyai tujuan yakni untuk mengidentifikasi, menilai, mengurangi, mengendalikan atau menghilangkan resiko-resiko yang terkait dengan pekerjaan, akan tetapi sampai sekarang masih ada kecelakaan kerja yang terjadi walaupun dalam jumlah kecil. Penulis ingin mengetahui tentang pengaruh penerapan Fundamental Safe Work Practice (FSWP) terhadap pencegahaan kecelakaan kerja dibagian Workover PT. ACS Duri. Penelitian ini menggunakan metode survei analitik kuantitatif, dengan desain Cross Sectional yang dilakukan mulai bulan Mei sampai dengan Juni Tahun 2012 dengan besar sampel 122 dari 360 orang yang berkerja di bagian Workover. Sampel diambil dengan menggunakan sistem Accidental Sampling, dan data diolah dengan menggunakan program komputer dengan menganalisa variabel independen berupa penerapan FSWP serta variabel dependen yaitu kecelakaan kerja dan diuji menggunakan Chi-square. Hasil penelitian menunjukkan bahwa, penerapan FSWP dapat mencegah kecelakaan kerja yang meliputi SOP dengan nilai $\mathrm{P}=0,01$ lebih kecil dari nilai $\alpha=0,05$ berarti ada hubungan bermakna antara penerapan SOP dengan kecelakaan kerja, PTW dengan nilai $\mathrm{P}=0,02$ lebih kecil dari nilai $\alpha=0,05$ berarti ada hubungan bermakna antara penerapan PTW dengan kecelakaan kerja, serta LOTO dengan nilai $\mathrm{P}=0,01$ lebih kecil dari nilai $\alpha=0,05$ berarti ada hubungan bermakna antara penerapan LOTO dengan kecelakaan kerja. Disimpulkan bahwa, penerapan FSWP dapat mengurangi/menurunkan angka kecelakaan kerja di bagian Workover, dan diharapkan bagi pihak manajemen HES untuk meningkatkan pengetahuan karyawan tentang aspek-aspek FSWP (SWA, Hazard Analysis, SOP, Access Control, PPE, MSDS, Housekeeping, PTW \& Other Safe Work Practices).
\end{abstract}

Kata Kunci: FSWP (SOP, PTW \& LOTO), Kecelakaan Kerja, PT ACS Duri

\begin{abstract}
PT. Asrindo Citraseni Satria (ACS) is a company engaged in oil and gas and is a sub contractor PT.CPI. PT. ACS has implemented FSWP whose objective which is to identify, assess, reduce, control or eliminate the risks associated with the work, but until now there is still a work accident that occurred even in small quantities. The author would like to know about the effect of application of the section Fundamental Safe Work Practice (FSWP) can prevent the accident in workover PT. ACS Duri. This research uses quantitative analytical survey, with the design of Cross Sectional conducted from May to June 2012 with a large sample of 122 of the 360 people who work in the workover. Samples were taken by using a system Accidental Sampling, and the data processed using a computer program to analyze the independent variables in the form of application as well as the dependent variable is FSWP occupational accidents and tested using Chi-square. The results showed that, the application of FSWP can prevent accidents which includes Standard Operating Procedure (SOP) with the value of $P=0.01$ is smaller than the value of $\alpha=0.05$ that means there are a significant correlation between the application of SOP with workplace accidents, PTW with a value of $P=0.02$ is more smaller than the value of $\alpha=0.05$ means that there are significant correlation between the application of Permit To Work (PTW) accidents, and tagged with a value of $P=0.01$ is smaller than the value of $\alpha=0.05$ means there is a significant correlation between the application of Log Out/Tag Out (LOTO) by accident. It was concluded that, the application of FSWP can reduce / reduce the number of occupational accidents in the workover, and is expected for the management of HES to improving the knowledge for employee about the aspects of FSWP (SWA, Hazard Analysis, SOP, Access Control, PPE, MSDS, Housekeeping, PTW \& Other Safe Work Practices).
\end{abstract}

Key words: FSWP (SOP, PTW \& LOTO), accidents, PT ACS Duri

\section{PENDAHULUAN}

Materi keselamatan kerja diatur dalam Undang-undang No. 1 Tahun 1970 yang ruang lingkupnya berhubungan dengan mesin, landasan tempat kerja dan lingkungan kerja, serta cara mencegah terjadinya kecelakaan dan penyakit akibat kerja, memberikan perlindungan kepada sumbersumber produksi sehingga dapat meningkatkan efesiensi dan produktivitas (Sugandi, D, 2005).

Alamat Korespondesi : Nopriadi, Universitas Andalas padang, HP : 085365915691, email: nopriadi_dhs@yahoo.com 
Keselamatan kerja atau Occupational Safety, dalam istilah sehari-hari sering disebut dengan safety saja, oleh American Society of Safety Engineers (ASSE) diartikan sebagai bidang kegiatan yang ditujukan untuk mencegah semua jenis kecelakaan yang ada kaitannya dengan lingkungan dan situasi kerja. Sedangkan secara filosofi diartikan sebagai suatu pemikiran dan upaya untuk menjamin keutuhan dan kesempurnaan baik jasmaniah maupun rohaniah tenaga kerja pada khususnya dan manusia pada umumnya serta hasil karya dan budayanya. Dari segi keilmuan diartikan sebagai suatu pengetahuan dan penerapannya dalam usaha mencegah kemungkinan terjadinya kecelakaan dan penyakit akibat kerja (Budiono, S.A.M, 2005).

Menurut perkiraan International Labour Organization (ILO), setiap tahun di seluruh dunia 2 juta orang meninggal karena masalah-masalah akibat kerja. Setiap tahun ada 270 juta pekerja yang mengalami kecelakaan akibat kerja dan 160 juta pekerja yang terkena penyakit akibat kerja. Biaya yang harus dikeluarkan untuk bahaya-bahaya akibat kerja sangat besar. ILO memperkirakan kerugian yang dialami sebagai akibat kecelakaan-kecelakaan dan penyakit-penyakit akibat kerja setiap tahun lebih dari US\$1,25 triliun (http :// repository usu ac.id_).

Di Indonesia diperkirakan setiap tahun, ribuan kecelakaan kerja terjadi di tempat kerja yang menimbulkan korban jiwa, kerusakan materi, dan gangguan produksi. Pada tahun 2007 menurut Jamsostek tercatat 65.474 kecelakaan yang mengakibatkan 1.451 orang meninggal, 5.326 orang cacat tetap dan 58.697 orang cedera ( $\mathrm{http}$ : repository.usu.ac.id).

Kerugian materi akibat kecelakaan juga besar seperti kerusakaan sarana produksi, biaya pengobatan dan kompensasi. Selama tahun 2007 kompensasi kecelakaan yang di keluarkan Jamsostek mencapai Rp. 165,95 miliar. Kerugian materi lainnya jauh lebih besar (Ramli, S. 2010).

Menurut Kepala Dinas Tenaga Kerja di Riau, menyebutkan bahwa sejak 5 tahun terakhir ini, jumlah kecelakaan kerja statis diangka 1.400 an kasus, sempat menurun tahun 2010 lalu dengan jumlah 1.300-an. Namun tahun 2011 meningkat mencapai 1.600-an kasus kecelakaan kerja. Sedangkan pertumbuhan pelaku usaha cukup besar setiap tahunnya. Hal itu berpotensi untuk terjadi peningkatan jumlah kecelakaan kerja kedepan (www.riauterkini.com).

Hasil inspeksi dan audit yang dilakukan oleh Chevron Pacific Indonesia (CPI) Management dan Tim HES beberapa tahun terakhir menunjukkan bahwa dalam beberapa hal di bidang keselamatan seharusnya lebih baik. Temuan-temuan dan hasil pengamatan itu memberikan peluang untuk perbaikan terutama di area dasar-dasar keselamatan. Berdasarkan inilah kemudian Management Duri OU mencanangkan fokus perbaikan di bidang fundamental safety untuk tahun 2002 dan 2003. Lebih lanjut kemudian fundamental safety didefinisikan sebagai 8 elemen keselamatan seperti tersebut di definisi umum sebelumnya. Fokus Fundamental Safety ini selanjutnya dimasukkan sebagai fokus untuk Operational Excellence (OE).

PT. ACS sudah menerapakan program Keselamatan dan Kesehatan Kerja (K3). Program Health Enviroment \& Safety (HES) Training, Safety Meeting, Behavior Base Safety (BBS), juga Fundamental Safe Work Practices (FSWP) sudah diterapkan demi mencegah terjadinya kecelakaan kerja dalam beroperasi.

Perusahaan mempunyai prosedur kerja yang aman dan spesifik, yang disesuaikan dengan jenis pekerjaan yang terkait dengan operasional perusahaan. Tujuan dari proses Managing Safe Work (MSW) atau di IndoAsia Business Unit (IBU) disebut sebagai FSWP yakni untuk mengidentifikasi, menilai, mengurangi, mengendalikan atau menghilangkan resiko-resiko yang terkait dengan pekerjaan. Proses ini menyediakan pengenalan dan evaluasi dari bahaya kerja, spersifikasi dari tindakan pengendalian, manajemen dari tindakan tersebut, pengendalian kerja, dan perilaku pendukung kerja aman (IBU FSWP Guidebook, 2011).

Berdasarkan data dari PT. ACS, kecelakaan kerja pada tahun 2009 sekitar 3 kejadian. Pada tahun 2010 hanya 1 kejadian, dan sedangkan pada tahun 2011 mencapai 8 kejadian seperti luka gores pada jari tengah floorman, mata crane swamper terkena percikan cairan baterai, jari kelingking derrickman terjepit dan lampu signal tertabrak tool pusher. Kejadian ini setiap tahunnya selalu berfluktuasi dan sebagian besar kejadian-kejadian tersebut diakibatkan karena penerapan FSWP seperti SOP untuk derrickman, floorman, crane swamper tidak berjalan sesuai dengan pedoman atau langkah-langkah yang ada dalam SOP.

Tujuan dari penelitian ini adalah untuk mengetahui pengaruh penerapan Fundamental Safe Work Practices (FSWP) terhadap pencegahan kecelakaan kerja pada bagian Workover di PT. ACS Duri.

\section{METODE}

Penelitian ini menggunakan metode survei analitik kuantitatif, dengan desain Cross Sectional, di mana penelitian ini bertujuan untuk mempelajari dinamika korelasi antara faktor-faktor resiko dengan efek, dengan cara pendekatan observasi atau pengumpulan data sekaligus pada suatu saat (Point Time Approach).

Penelitian ini dilakukan mulai bulan Mei sampai dengan Juni Tahun 2012 dengan besar sampel 122 dari 360 orang yang berkerja di bagian Workover. 
Data yang dikumpulkan dalam dua jenis yaitu data primer didapatkan melalui penyebaran pertanyaan (kuesioner) kepada seluruh responden di lapangan dan data sekunder didapatkan dari data-data yang ada di perusahaan. Data yang diperoleh langsung diolah dengan menggunakan program komputer dengan menganalisa variabel independen berupa penerapan FSWP serta variabel dependen yaitu kecelakaan kerja. Analisis data yang digunakan adalah analisis univariat dan analisis bivariat serta diuji menggunakan Chisquare.

HASIL

Analisis Univariat

Tabel 1

Distribusi Frekuensi Variabel Penelitian pada

Responden PT. Asrindo Cintaseni Satria Duri Th. 2012

\begin{tabular}{|c|c|c|}
\hline $\begin{array}{c}\text { Variabel } \\
\text { Penelitian }\end{array}$ & Jumlah & $\begin{array}{c}\text { Persentase } \\
(\%)\end{array}$ \\
\hline \multicolumn{3}{|c|}{ Kecelakaan Kerja } \\
\hline Pernah & 3 & 2,5 \\
\hline Tidak Pernah & 119 & 97,5 \\
\hline \multicolumn{3}{|l|}{ Penerapan SOP } \\
\hline Ada & 119 & 97,5 \\
\hline Tidak ada & 3 & 2,5 \\
\hline \multicolumn{3}{|c|}{ Penerapan PTW } \\
\hline Ada & 118 & 96,7 \\
\hline Tidak ada & 4 & 3,3 \\
\hline \multicolumn{3}{|c|}{ Penerapan LOTO } \\
\hline Ada & 119 & 97,5 \\
\hline Tidak ada & 3 & 2,5 \\
\hline Jumlah & 122 & 100,0 \\
\hline
\end{tabular}

Dari tabel 1 dapat diketahui bahwa lebih banyak responden yang menyatakan : tidak pernah mengalami kecelakaan kerja $(97,5 \%)$, telah ada penerapan SOP $(97,5 \%)$, telah ada penerapan PTW $(96,7 \%)$ dan telah ada penerapan LOTO $(97,5 \%)$.

\section{Analisis Bivariat}

\section{Hubungan antara Penerapan SOP dengan} Kecelakaan Kerja

Penerapan SOP mempunyai proporsi lebih besar yaitu $118(99,2 \%)$ untuk tidak terjadinya kecelakaan kerja dibandingkan dengan tidak ada penerapan SOP yaitu 1 (33,3\%). Hasil uji statistik dengan menggunakan uji chi square diperoleh nilai $\mathrm{P}$ $=0,01$ lebih kecil dari nilai $\alpha=0,05$. Hal ini dapat disimpulkan bahwa terdapat pengaruh antara penerapan SOP dengan pencegahan kecelakaan kerja (lihat tabel 2).

\section{Hubungan antara Penerapan PTW dengan Kecelakaan Kerja}

Penerapan PTW menpunyai proporsi lebih besar yaitu $117 \quad(99,2 \%)$ untuk tidak terjadinya kecelakaan kerja dibandingkan dengan tidak ada penerapan PTW yaitu 2 (50\%). Hasil uji statistik dengan menggunakan uji chi square diperoleh nilai $\mathrm{P}$ $=0,02$ lebih kecil dari nilai $\alpha=0,05$. Hal ini dapat disimpulkan bahwa terdapat pengaruh antara penerapan PTW dengan pencegahan kecelakaan kerja (lihat tabel 3).

\section{Hubungan antara Penerapan LOTO dengan Kecelakaan Kerja}

Penerapan LOTO menpunyai proporsi lebih besar yaitu $118 \quad(99,2 \%)$ untuk tidak terjadinya kecelakaan kerja dibandingkan dengan tidak ada penerapan LOTO yaitu 1 (33,3\%). Hasil uji statistik dengan menggunakan uji chi square diperoleh nilai $\mathrm{P}=0,01$ lebih kecil dari nilai $\alpha=0,05$. Hal ini dapat disimpulkan bahwa terdapat pengaruh antara penerapan LOTO dengan pencegahan kecelakaan kerja (lihat tabel 4).

Tabel 2

Hubungan antara Penerapan SOP dengan Kecelakaan Kerja di bagian workover PT. Asrindo Citraseni Satria Duri

\begin{tabular}{|c|c|c|c|c|c|c|c|}
\hline \multirow{3}{*}{ Penerapan SOP } & \multicolumn{4}{|c|}{ Kecelakaan Kerja } & \multirow{2}{*}{\multicolumn{2}{|c|}{ Total }} & \multirow{3}{*}{ P Value } \\
\hline & \multicolumn{2}{|c|}{ Tidak Pernah } & \multicolumn{2}{|c|}{ Pernah } & & & \\
\hline & $\mathbf{n}$ & $\%$ & $\mathbf{n}$ & $\%$ & $\mathbf{N}$ & $\%$ & \\
\hline Tidak Ada & 1 & 33,3 & 2 & 66,7 & 3 & 100 & \\
\hline Ada & 118 & 99,2 & 1 & 0,8 & 119 & 100 & 0,01 \\
\hline Total & 119 & 97,5 & 3 & 2,5 & 122 & 100 & \\
\hline
\end{tabular}

Tabel 3

Hubungan antara Penerapan PTW dengan Kecelakaan Kerja di bagian workover PT. Asrindo Citraseni Satria Duri

\begin{tabular}{|c|c|c|c|c|c|c|c|}
\hline \multirow{3}{*}{ Penerapan PTW } & \multicolumn{4}{|c|}{$\begin{array}{c}\text { Kecelakaan Kerja } \\
\end{array}$} & \multirow{2}{*}{\multicolumn{2}{|c|}{ Total }} & \multirow{3}{*}{ P Value } \\
\hline & \multicolumn{2}{|c|}{ Tidak Pernah } & \multicolumn{2}{|c|}{ Pernah } & & & \\
\hline & $\mathbf{n}$ & $\%$ & $\mathbf{n}$ & $\%$ & $\mathbf{N}$ & $\%$ & \\
\hline Tidak Ada & 2 & 50 & 2 & 50 & 4 & 100 & \\
\hline Ada & 117 & 99,2 & 1 & 0,8 & 118 & 100 & 0,02 \\
\hline Total & 119 & 97,5 & 3 & 2,5 & 122 & 100 & \\
\hline
\end{tabular}


Tabel 4

Hubungan antara Penerapan LOTO dengan Kecelakaan Kerja di bagian workover PT. Asrindo Citraseni Satria Duri

\begin{tabular}{|c|c|c|c|c|c|c|c|}
\hline \multirow{3}{*}{ Penerapan LOTO } & \multicolumn{4}{|c|}{ Kecelakaan Kerja } & \multirow{2}{*}{\multicolumn{2}{|c|}{ Total }} & \multirow{3}{*}{ P Valuc } \\
\hline & \multicolumn{2}{|c|}{ Tidak Pernah } & \multicolumn{2}{|c|}{ Pernah } & & & \\
\hline & $\mathbf{n}$ & $\%$ & $\mathbf{n}$ & $\%$ & $\mathbf{N}$ & $\%$ & \\
\hline Tidak Ada & 1 & 33,3 & 2 & 66,7 & 3 & 100 & \\
\hline Ada & 118 & 99,2 & 1 & 0,8 & 229 & 100 & 0,01 \\
\hline Total & 119 & 97,5 & 3 & 2,5 & 122 & 100 & \\
\hline
\end{tabular}

\section{PEMBAHASAN}

\section{Pengaruh antara Penerapan SOP dengan Kecelakaan Kerja}

Berdasarkan hasil analisis bivariat, ada pengaruh antara penerapan SOP dengan pencegahan kecelakaan kerja. Karena dari hasil uji statistik Chisquare yang dilakukan, angka $\mathrm{P}$ value yang didapat adalah 0,01 yang berarti lebih kecil dari $\alpha=0,05$.

Hasil penenilian ini sesuai dengan buku IndoAsia Business Unit (IBU) FSWP Guidebook PT. Chevron Pacific Indonesia (PT. CPI) tahun 2011, yang membahas tentang Prosedur Operasi Standar (SOP) yaitu penerapan SOP bertujuan untuk mencegah terjadinya kecelakaan kerja. Karena SOP itu adalah langkah-langkah kerja tertulis yang terfokus pada pelaksanaan pekerjaan untuk mengurangi resiko kerugian dan mempertahankan kehandalan dan hal itu dapat terwujud apabila karyawan bekerja selalu mengikuti langkah-langkah yang ada dalam SOP.

Dalam Vico Indonesia menyatakan bahwa, pekerjaan tanpa penerapan SOP termasuk dalam kategori lemahnya pengendalian manejemen yang tercantum dalam dasar-dasar program. Sedangkan menurut Bird dan Germain dalam Katia (2009), menyatakan tidak adanya penerapan SOP merupakan penyebab dasar terjadinya kecelakaan kerja yang tercantum dalam ILCI Loss Causation Model.

Penelitian ini juga didukung dari hasil observasi peneliti selama melakukan penelitian, SOP sudah diterapakan dan bahkan selalu diadakan pelatihan internal tentang SOP. Bahkan lebih dari itu, SOP yang diterapkan oleh PT.CPI dan sub kontraktornya sudah termasuk Q-SOP (SOP Qualified) yang kemungkinan belum diterapkan oleh perusahaan manapun. Maka dari itu, dengan ada atau tidak adanya penerapan SOP dapat dijadikan pertimbangan/acuan dalam investigasi kecelakaan kerja oleh PT.ACS.

Bahwa dengan rendahnya kasus kecelakaan kerja di PT.ACS, merupakan tingkat keberhasilan dari penerapan SOP oleh PT. ACS tersebut. Sedangkan untuk kasus kecelakaan kerja yang masih terjadi, bisa kemungkinan disebabkan oleh faktor lain seperti Unsafe Action atau Unsafe Condition.

\section{Pengaruh antara Penerapan PTW dengan Kecelakaan Kerja}

Berdasarkan hasil analisis bivariat, ada pengaruh antara penerapan PTW dengan pencegahan kecelakaan kerja. Karena dari hasil uji statistik Chisquare yang dilakukan, angka $\mathrm{P}$ value yang didapat adalah 0,02 yang berarti lebih kecil dari $\alpha=0,05$.

Penelitian ini sesuai dengan buku Corporate SH\&E (1999); yang menyatakan bahwa tujuan utama dari proses izin kerja adalah untuk membentuk komunikasi di antara kelompok kerja lintas-fungsi di suatu tempat kerja dalam melakukan pekerjaan untuk mengingatkan pekerja akan bahaya yang mungkin timbul dan untuk memastikan bahwa pekerjaan tersebut selamat untuk dilakukan.

Sama halnya dengan SOP, izin kerja pun termasuk dalam kategori lemahnya pengendalian manajemen jika suatu pekerjaan tidak diterapkannya izin kerja. Didukung oleh teori ILCI Loss Causation Model yang dikemukakan oleh Bird dan Germain dalam Katia (2009), beliau menyatakan jika tidak ada penerapan izin kerja untuk suatu pekerjaan, itu merupakan penyebab dasar untuk terjadinya kecelakaan kerja. Jadi makna dari teori ini adalah suatu kecelakaan kerja dapat dihindari/dicegah dengan penerapan izin kerja.

Penelitian ini juga didukung oleh hasil observasi peneliti selama melaksanakan penelitian yaitu, seluruh karyawan telah memahami tentang PTW karena seluruh karyawan harus mengikuti pelatihan tentang PTW baik internal maupun eksternal. Selain dari itu, proses perizinan ini sangat mudah dilakukan oleh para karyawan. Mengingat semua prosedur sudah dibakukan dan seluruh karyawan sudah mengerti tugas dan tanggungjawab masing-masing sehingga tidak ada keterhambatan dalam mengurus izin kerja.

Maka dengan adanya pengaruh antara PTW dengan pencegahan kecelakaan kerja di bagian Workover PT. ACS Duri, dapat dinyatakan bahwa ada atau tidak adanya penerapan PTW disuatu perusahaan dapat menjadi acuan untuk mencari penyebab kecelakaan yang terjadi di lingkungan kerja tersebut. 
Tingkat keberhasilan penerapan PTW yang merupakan salah satu aspek dari FSWP yaitu rendahnya kasus kecelakaan kerja yang terjadi di PT.ACS. Meskipun kasus kecelakaan keerja masih terjadi, kemungkinan disebabkan oleh kurangnya pengawasan lapangan.

\section{Pengaruh antara Penerapan LOTO dengan Kecelakaan Kerja}

Berdasarkan hasil analisis bivariat, ada pengaruh antara penerapan PTW dengan pencegahan kecelakaan kerja. Karena dari hasil uji statistik Chisquare yang dilakukan, angka $\mathrm{P}$ value yang didapat adalah 0,01 yang berarti lebih kecil dari $\alpha=0,05$.

Penelitian ini jelas sesuai dengan makna yang terkandung dalam buku Corporate SH\&E (1999) yang membahas tentang LOTO, yaitu LOTO itu digunakan untuk mencegah terjadinya kecelakaan kerja. Karena LOTO itu digunakan untuk mencegah timbulnya energi yang tiba-tiba dan tidak diharapkan dari mesin, peralatan, fasilitas proses produksi yang sedang diperbaiki, yang dapat mencederai seseorang atau merusak peralatan.

Menurut teori elemen kunci K3 terdapat beberapa tahapan mulai dari peraturan, perencanaan, pelaksanaan, pengukuran dan evaluasi serta peninjauan ulang SMK3. LOTO merupakan bagian dari pengendalian alat/mesin yang tergolong dalam tahap perencanaan. Hal ini berarti, LOTO itu diterapkan untuk sebuah rencan yaitu untuk mencegah terjadinya kecelakaan kerja yang berhubungan dengan alat/mesin.

Hasil penelitian ini juga didukung dari hasil observasi peneliti selama melakukan penelitian yaitu, semua yang dibutuhkan dalam proses

pemberian/pemasangan LOTO sudah tersedia baik itu dari gembok maupun labelnya. Dari segi teknis yang lain, seperti tugas dan tanggungjawan serta orang yang mempunyai wewenang dalam pemasangan dan pelepasan LOTO sudah ditetapkan. Sehingga tidak ada alasan lagi untuk menghambat atau mengulur waktu pemasangan LOTO, walaupun demikian masih ada kemungkinan sebagian karyawan yang belum paham mengenai LOTO. Hal itu dapat dikaitkan dengan masa kerja karyawan yang masih tergolong baru, sehingga mereka masih kurang pengetahuan dan pengalaman. Untuk masalah seperti ini, koordinator HES harus selalu memberikan pelatihan internal kepada seluruh karyawan yang bekerja di lokasi. Dengan adanya pengaruh antara penerapan LOTO dengan kecelakaan kerja, maka dari itu ada atau tidak adanya penerapan LOTO disuatu perusahaan dapat menjadi acuan untuk mencari penyebab kecelakaan yang terjadi di lingkungan kerja tersebut.

Bahwa dengan rendahnya kasus kecelakaan kerja yang berhubungan dengan LOTO membuktikan, PT.ACS benar-benar komit dalam penerapan FSWP di perusahaannya, dan ini merupakan tingkat keberhasilan dalam penerapan LOTO.

\section{KESIMPULAN}

Ada pengaruh yang bermakna antara penerapan SOP, penerapan PTW dan penerapan LOTO dengan pencegahan kecelakaan kerja.

\section{SARAN}

\section{Bagi PT. ACS}

Diharapkan pihak manajemen HES/Koordinator HES untuk terus meningkatkan program Fundamental Safe Work Practice (FSWP) yang telah dibuktikan sangat berpengaruh dalam pencegahan kecelakaan kerja dengan pemberian pelatihan baik eksternal maupun internal perusahaan dan diharapkan juga HES Field untuk meningkatkan pengawasan di lapangan, agar temuan-temuan di lapangan dapat dilaporkan dan tercatat dan juga untuk memantau kegiatan di lapangan yang kemungkinan masih kurang berjalan.

Bagi Pekerja

Diharapkan para pekerja lapangan tidak hanya menunggu untuk mendapatkan ilmu dan pengetahuan tentang keselamatan kerja, bertanya dan minta penjelasanlah kepada koordinator HES mengenai halhal yang belum dimengerti serta melaporkan kejadian kecelakaan kerja yang terjadi, agar ada tindakan perbaikan dari pihak manajemen.

Bagi Peneliti Selanjutnya

Disarankan untuk meneliti beberapa aspek FSWP seperti Stop Work Authority (SWA), Hazard Analysis, Access Control, Personal Protective Equipment (PPE), Material Safety Data Sheet (MSDS), Housekeeping yang belum diteliti atau melanjutkan penelitian ini untuk mengetahui penyebab terjadinya kecelakaan kerja walaupun SOP, PTW dan LOTO telah dilaksanakan.

\section{UCAPAN TERIMA KASIH}

Ucapan terima kasih ditujukan kepada Bapak Nopriadi, Bapak Masribut, Manejer HRD PT. ACS Bapak Hendra, Manejer HES Bapak Ridwan, pembimbing lapangan Ibu Dina.

\section{DAFTAR PUSTAKA}

Budiono,A.M.S. (2005). Umum. Bunga Rampai HIPERKES dan Keselamatan Kerja. CV. Nugraha Sentosa. Bandung

http: $\begin{array}{ll} & \text { utusanriau.com/news/detail/3095/2012/01/10/2 } \\ & \text { 011,-kecelakaan-kerja-di-riau-naik-300-orang: } \\ \text { diakses 09 Februari 2012 }\end{array}$


http://repository.usu.ac.id/bitstream/123456789/23456/ 5/Chapter\%20I.pdf : diakses 18 Februari 2012

http://www.riauterkini.com/usaha.php?arr=42721 diakses 15 Februari 2012

IndoAsia, Chevron (2011). IBU FSWP Guidebook (Fundamental Safe Work Practices). Sentral Senayan $1 \& 2$ Office Tower, Jakarta (Tidak Dipublikasikan).
IndoAsia, Chevron (2006). FSWP (Fundamental Safe Work Practices) (Tidak Dipublikasikan).

Ramli, S .(2010a). Sistem Manajemen Keselamatan dan Kesehatan Kerja OHSAS 18001, Dian Rakyat, Jakarta.

Sugandi, D. (2005). Keselamatan Kerja. Bunga Rampai HIPERKES dan Keselamatan Kerja. CV. Nugraha Sentosa. Bandung 